\title{
Scheduled Substance Administration
}

National Cancer Institute

\section{Source}

National Cancer Institute. Scheduled Substance Administration. NCI Thesaurus. Code C95336.

A substance administration that is anticipated to occur at some time in the future and has been assigned a time or date when that activity is to be performed. 